\title{
Nano patterning of AISI 316L stainless steel with Nonlinear Laser Lithography: Sliding under dry and oil-lubricated conditions
}

\author{
Iaroslav Gnilitskyi ${ }^{a}$, Fabio Rotundo ${ }^{\mathrm{b}}$, Carla Martini ${ }^{\mathrm{b}}$, Ihor Pavlov ${ }^{\mathrm{c}}$, Serim Ilday ${ }^{\mathrm{c}}$, \\ Evgeny Vovk ${ }^{\mathrm{d}, \mathrm{e}}$, Fatih Ömer Ilday ${ }^{\mathrm{c}, \mathrm{f}}$, Leonardo Orazi ${ }^{\mathrm{a}, *}$ \\ a Department of Sciences and Methods for Engineering, University of Modena and Reggio Emilia, Italy \\ ${ }^{\mathrm{b}}$ Industrial Engineering Department, University of Bologna, Italy \\ ${ }^{\mathrm{c}}$ Department of Physics, Bilkent University, Turkey \\ ${ }^{\mathrm{d}}$ Department of Chemistry, Bilkent University, Turkey \\ e Boreskov Institute of Catalysis, Russia \\ ${ }^{\mathrm{f}}$ Department of Electrical and Electronics Engineering, Bilkent University, Turkey
}

\section{A R T I C L E I N F O}

\section{Article history:}

Received 24 November 2015

Received in revised form

23 January 2016

Accepted 11 March 2016

Available online 22 March 2016

Keywords:

Laser

Nano texturing

Wear

LIPSS

\begin{abstract}
A B S T R A C T
Femtosecond laser-based Nonlinear Laser Lithography (NLL) was applied to AISI 316L stainless steel, which requires surface modification to achieve satisfactory tribological behaviour. NLL advances over the well-known Laser Induced Periodic Surface Structures (LIPSS) in terms of uniformity and long-range order of high speeds, over large areas. A galvanometric scanner head was used for an high production rate. Dry and lubricated sliding tests, considering different orientations of the nanotexture showed that COF values after NLL treatment are significantly lower. In lubricated tests, COF values of NLL-treated surfaces are nearly half the values of untreated surfaces, whereas the difference further increases when measured in dry conditions, where the orientation of the surface texturing influences the results.
\end{abstract}

(c) 2016 Elsevier Ltd. All rights reserved.

\section{Introduction}

Austenitic stainless steels are widely used in chemical, biomedical and nuclear applications, because of their corrosion resistance and non-magnetic properties [1]. However, in applications involving steel-on-steel sliding contacts, such as pumps, valves and bearings, the tribological behaviour of AISI 316L may be unsatisfactory [2]. Lubricants and coatings [3] are often used to reduce friction and wear, but lubricants have well-known drawbacks (such as their environmental impact) and coatings may significantly affect the design of the component and its final cost [4]. Among alternative surface modification technologies for the improvement of tribological behaviour, the generation of textured surfaces with laser-based technologies recently attracted a significant research interest. Surface texturing can be achieved by various techniques: in particular, the use of a laser beam detected by a galvanometric scanner permits to generate sets of pits, grooves or ripples that are regularly or randomly distributed. As regards the application of laser texturing on steel surfaces, in [5] Andersson et al. used a UV laser to produce grooves with an aspect ratio of about 1 , which were reported to improve wear-resistance

\footnotetext{
* Corresponding author.

E-mail address: leonardo.orazi@unimore.it (L. Orazi).
}

of the material (M2 high-speed steel) and decrease the Coefficient Of Friction (COF). An experimental investigation of the tribological properties of 17-4 PH stainless steel was conducted by Qiu et al. [6] by generating dimples on the surface using a laser marking machine, where large dimples helped to reduce the COF. On the other hand, the authors pointed out an increase in the wear ratio, probably due to the reduction of the contact area. Ramesh et al. [7] presented the results of unidirectional sliding tests in lubricated conditions, showing a decrease in COF after surface texturing of 17-4 PH stainless steel by creating grooves with diameters between 30 and $110 \mu \mathrm{m}$. Generation of dimples with relatively large dimensions (15 to $800 \mu \mathrm{m}$ ) on engine parts using a nanosecond fiber laser was reported by Braun et al. [8]: tribological tests conducted on carbon steel (normalized C85) and bearing steel $(100 \mathrm{Cr} 6)$ performed in conditions mimicking realistic engine working conditions, showed a COF decrease up to $80 \%$. The use of a femtosecond laser to generate grooves 50 to $100 \mu \mathrm{m}$ wide on the surface of $100 \mathrm{Cr} 6$ steel was reported by Scaraggi et al. [9] thus obtaining a reducing of COF in lubricated conditions.

In all these papers, the characteristic dimensions of the patterns on the surface are rather large. They are determined by the minimum laser spot size, always larger than the laser wavelength. However, theory suggests that the tribological properties could be further improved by decreasing the dimensions of these textures 
to the nanoscale, as pointed out in the recent theoretical study cited by Daschiel et al. [10].

The formation of ripples, grooves and nanostructures on material surfaces generally known as Laser Induced Periodic Surface Structures (LIPSS) is a well-known phenomenon that has been investigated on various materials such as metals [11-13], dielectrics $[11,14,15]$ and semiconductors [16]. In recent years the generation of nanostructures on different material surfaces has attracted a lot of attention from researchers due to the potentially implementation of these methods in various manufacturing processes [11,17]. In particular in Bonse et al. [18,19] the effects of LIPSS on the tribological properties of martensitic stainless steel, chromium steel and titanium alloys were investigated. While no appreciable results were measured on steels the effects on titanium alloy appeared to be encouraging. However, some technical limitations must be solved such as low-speed, problems of material control and lack of uniformity and repeatability over large areas $[20,21]$. Recently, a technique called Nonlinear Laser Lithography (NLL) has been introduced [22], which allows fabrication of extremely uniform, self-similar nanostructures, with excellent long-range repeatability and production rate. The technique has been reported to be applicable to various materials, even with non-planar, curved and flexible surfaces. NLL essentially generates surface nanostructures by utilizing nonlinear feedback mechanisms arising from the interaction of femtosecond laser pulses with the material surface as well from the laser-initiated chemical reactions. Key features, such as superior uniformity and ability to process non-planar surfaces has been presented as a direct consequence of the self-regulation, provided by these feedback mechanisms.

In the present work, NLL technique is used to provide an effective and low-cost method for the fabrication of large-area nanotextured metal surfaces. Specially, we report on generation of highly uniform nanostructures on AISI 316L austenitic stainless steel surface, in order to improve its tribological properties. The sliding behaviour of the NLL-induced nanostructures was assessed by dry (block-on-ring) and lubricated (ball-on-disk contact geometry) sliding tests, using different counterbody materials. Moreover, we evaluated the effect of the orientation of nanostructures with respect to the sliding direction (parallel/perpendicular) on frictional properties.

\section{Materials and methods}

\subsection{Material}

The material under investigation is the AISI 316L austenitic stainless steel, despite its lower tribological performance, it is widely used where contact with food, liquids and drugs require an elevated resistance to corrosion and high chemical stability. In the case of relative movement between parts like coaters or mixers the design of the system must assure a low contact pressure in order to avoid rapid damage.

The material was supplied as extruded bars in the ashomogenized condition followed by conventional solution treatment and presenting a hardness of $230 \mathrm{HV}_{0.1}$. The chemical composition of AISI 316L, measured by spark optical emission spectroscopy, is reported in Table 1.

\subsection{NLL-induced surface texturing}

NLL-induced nanostructures were generated using a custombuilt Yb-doped fiber laser system as shown in Fig. 1a. The setup provides pulses of $270 \mathrm{fs}$ at a central wavelength of $1037 \mathrm{~nm}$ with a spectral width of $15 \mathrm{~nm}$. The pulse repetition rate was set to
Table 1

Chemical composition of the AISI 316L stainless steel measured via spark optical emission spectroscopy.

\begin{tabular}{llllllll}
\hline $\mathbf{C} \%$ & Mn $\%$ & Si $\%$ & Cr $\%$ & Ni $\%$ & Mo $\%$ & P \% & S \% \\
\hline 0.024 & 1.350 & 0.400 & 16.870 & 10.050 & 2.060 & 0.031 & 0.029 \\
\hline
\end{tabular}

$200 \mathrm{kHz}$ and at this frequency the setup can generate up to $8 \mu \mathrm{J}$ pulses, resulting in an average power of $1.6 \mathrm{~W}$. The laser beam was then delivered to the surface thank to a galvanometric scanner (SCANLAB SCANCube III) equipped with a $56 \mathrm{~mm}$ focal length $\mathrm{f}$ theta lens.

Using this configuration, areas of $7 \times 5 \mathrm{~mm}^{2}$ on the material surface were NLL-treated in parallel (SS $\|$ ) and perpendicular $(\mathrm{SS} \perp)$ orientations of the ripples with respect to the scanning direction, and with steps between scanning lines fixed to $5 \mu \mathrm{m}$. The schematics shown in Fig. $1 \mathrm{~b}$ and $\mathrm{c}$ describe the mutual directions of the polarization plane $\boldsymbol{E}$, the scanning direction of the beam $\boldsymbol{v}_{\boldsymbol{S}}$ and the sliding direction $\boldsymbol{v}_{\boldsymbol{R}}$ during tribological tests. The scanning speed was set to $200 \mathrm{~mm} \mathrm{~s}^{-1}$ for all experiments. Table 2 shows the laser parameters used in the NLL-treatments of the samples $\mathrm{SS} \|$ and $\mathrm{SS} \perp$ where $\theta_{P}$ is the angle between direction along the nanostructures and the sliding $\operatorname{direction}\left(\boldsymbol{v}_{\boldsymbol{R}}\right) ; E_{p}$ is the energy per pulse; $\tau_{P}$ is the pulse duration, $f$ is the repetition rate; $\delta_{S}$ is the step; $d$ is the spot diameter; and $v_{S}$ is the scanning speed.

\subsection{Structural and chemical analysis}

The surface morphology was observed in secondary electrons imaging mode using a Variable Pressure Scanning Electron Microscopy coupled with Energy Dispersive Spectroscopy (VP-SEM Zeiss EVO 50 with Oxford Instruments Inca 350 EDS microprobe) and a FEI Nova NanoSEM 450 equipped with X-EDS Bruker QUANTAX-200. The surface roughness was measured using an atomic force microscope (AFM) operating in non-contact optical mode. The roughness was described by the arithmetic mean surface roughness $\left(R_{a}\right)$ and the mean peak to valley height $\left(R_{z}\right)$ that were calculated from the surface profiles. XPS analyses were performed utilizing a SPECS spectrometer equipped with a PHOIBOS hemispherical energy analyzer and a monochromatic Al K $\alpha$ X-ray irradiation ( $h \nu=1486.74 \mathrm{eV}, 350 \mathrm{~W}$ ) source. The Fe 2p, Cr 2p, Ni 2p, Mo 3d, C $1 \mathrm{~s}$, and $\mathrm{O} 1 \mathrm{~s}$ photoelectron core level spectra were monitored and analyzed. All spectra were calibrated using the $C$ $1 \mathrm{~s}$ main peak with binding energy of $284.6 \mathrm{eV}$. The photoelectron lines were assigned in accordance with XPS handbook [23]. The atomic concentrations of the elements were calculated by taking into account of corresponding relative sensitivity factors in CasaXPS software program.

\subsection{Tribological tests}

The tribological behaviour of the NLL-treated AISI316L surfaces was studied in sliding conditions, by means of two experimental configurations: (i) dry-sliding tests (unidirectional motion) in a block-on-ring configuration and (ii) lubricated tests (reciprocating motion) in a ball-on-disk configurations, so as to explore different contact conditions. Two orientations of the nanopatterned surface were tested, in order to identify which one is more effective in limiting adhesion phenomena: nanostructures parallel to the sliding direction $(\mathrm{SS} \|)$ or perpendicular to the sliding direction $(\mathrm{SS} \perp)$. Dry sliding test were carried out via a slider-on-cylinder tribometer (block-on-ring contact geometry, ASTM G77 [24]), according to the schematic of Fig. 2a. The sliders (prismatic blocks, $5 \times 5 \times 70 \mathrm{~mm}^{3}$ ) were machined from AISI 316L and different areas on them were treated according to the parameters of Table 2. Two different steels 
a

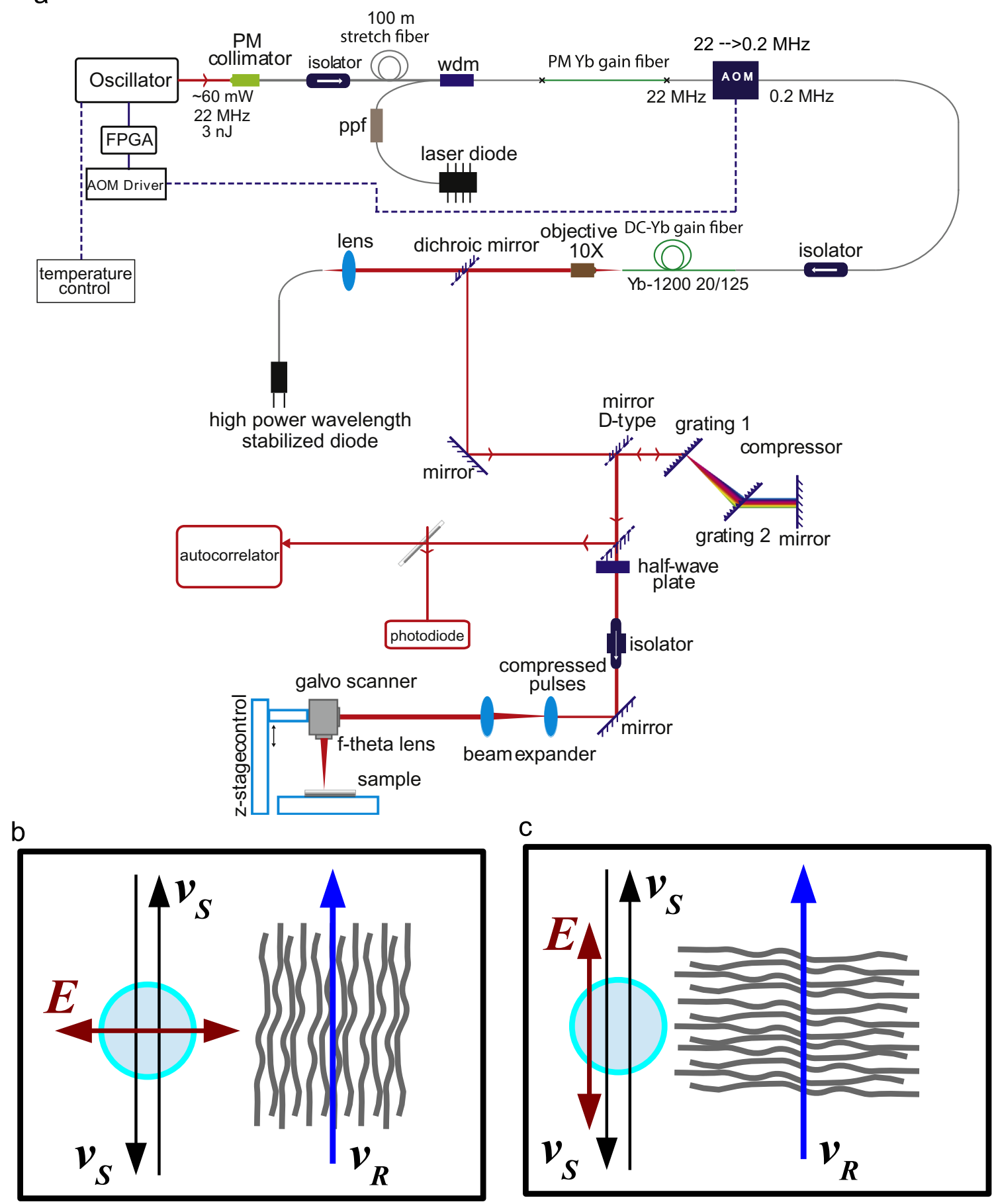

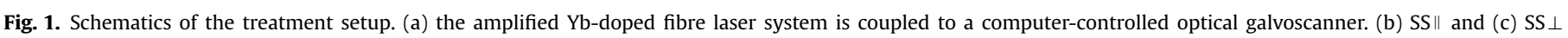
configurations. Figures show the polarization plane $\boldsymbol{E}$, the scanning direction of the beam $\boldsymbol{v}_{\boldsymbol{S}}$ and the sliding direction $\boldsymbol{v}_{\boldsymbol{R}}$ during the tribological test.

Table 2

The laser parameters used for the NLL-treatment.

\begin{tabular}{|c|c|c|c|c|c|c|}
\hline $\begin{array}{l}\text { code } \\
\text { - }\end{array}$ & $\begin{array}{l}\theta_{P} \\
{\left[^{\circ}\right]}\end{array}$ & $\begin{array}{l}E_{p} \\
{[\mathrm{~nJ}]}\end{array}$ & $\begin{array}{l}\tau_{P} \\
{[\mathrm{fs}]}\end{array}$ & $\begin{array}{l}f \\
{[\mathrm{kHz}]}\end{array}$ & $\begin{array}{l}\delta_{S} \\
{[\mu \mathrm{m}]}\end{array}$ & $\begin{array}{l}v_{S} \\
{[\mathrm{~mm} / \mathrm{s}]}\end{array}$ \\
\hline SS $\|$ & $0^{\circ}$ & 250 & 270 & 200 & 5 & 200 \\
\hline $\mathrm{SS} \perp$ & $90^{\circ}$ & 250 & 270 & 200 & 5 & 200 \\
\hline
\end{tabular}

were chosen as counterface material (i.e. rotating cylinders with $40 \mathrm{~mm}$ diameter): (i) untreated AISI 316L austenitic stainless steel (so as to assess the behaviour of self-mating tribological couples), with hardness of $285 \mathrm{HV}_{0.05}$ and surface roughness $R_{a}$ of $0.10 \mu \mathrm{m}$ and (ii) SAE52100 steel (EN100Cr6, which is a rather typical countermaterial for tribological tests, used also in lubricated tests as described below), with hardness of 62 HRC and surface roughness Ra of $0.10 \mu \mathrm{m}$. The block-on-ring geometry was selected considering its ability to reproduce sliding conditions which occur in unidirectional sliding systems involving austenitic stainless steel components (such as guides and components for packaging equipment) [25]. Sliding tests were carried out at ambient temperature $\left(22 \pm 2{ }^{\circ} \mathrm{C}\right)$ and humidity ( $\left.50 \pm 10 \mathrm{RH} \%\right)$, with a normal load of $5 \mathrm{~N}$ (corresponding to a maximum Hertzian contact pressure of $41 \mathrm{MPa}$ calculated according to the equations for the contact between two 
a

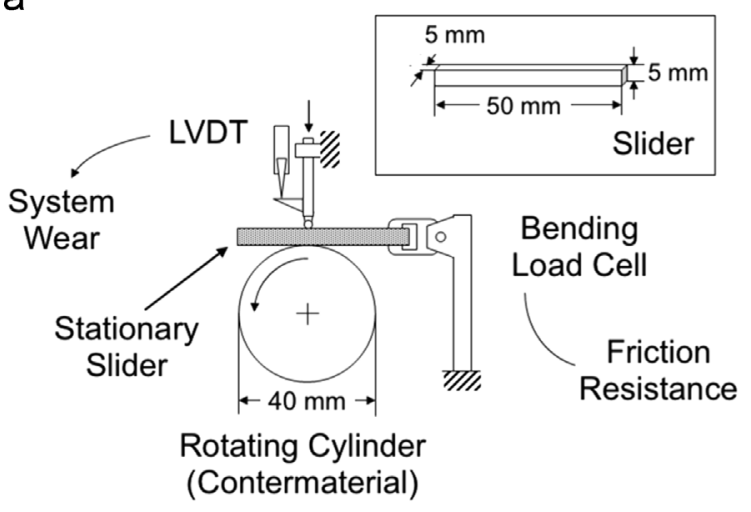

b

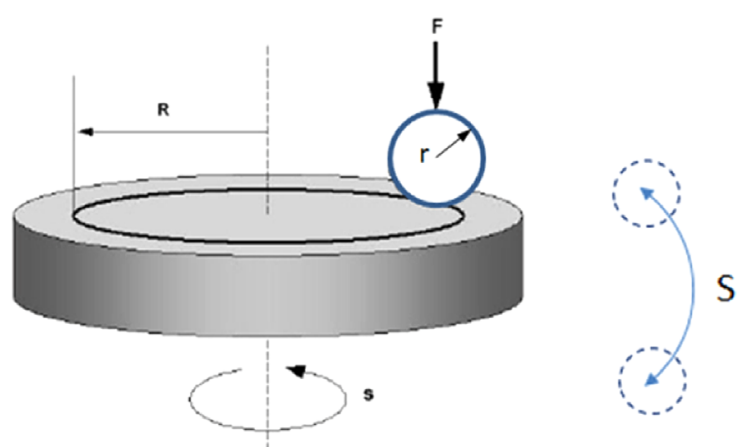

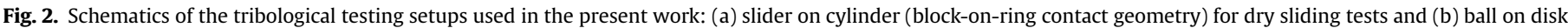
(pin-on-disk contact geometry) in reciprocating mode, with indication of stroke length (S), for lubricated sliding tests.

cylinders with parallel axes [26]), a linear relative speed $v_{R}$ of $0.3 \mathrm{~m} \mathrm{~s}^{-1}$ and a maximum sliding distance of $100 \mathrm{~m}$.

Lubricated sliding tests were carried out by a ball-on-disk tribometer (pin-on-disk contact geometry, ASTM:G99 [27]), according to the schematic of Fig. 2b. In lubricated tests, AISI 316L steel (NLL-treated and untreated) was used as rotating sample $\left(30 \times 30 \mathrm{~mm}^{2}\right.$ plates, thickness: $\left.5 \mathrm{~mm}, R_{a}: 0.20 \mu \mathrm{m}\right)$, while EN100Cr6 steel balls (diameter: $6 \mathrm{~mm}$, Vickers hardness: 750 $\mathrm{H} V_{0.1}, R_{a}: 0.10 \mu \mathrm{m}$ ) were the stationary counterbody.

The lubricated sliding test were performed with both disk and ball immersed in lubricating oil Mobil Univis N46, under normal loads of $1 \mathrm{~N}$ (corresponding to a maximum Hertzian contact pressure of $635 \mathrm{MPa}$, calculated according to the equations for the contact between spheres [26]), in reciprocating mode with a track radius (R) of $7.2 \mathrm{~mm}$, a stroke distance $(\mathrm{S})$ of $2 \mathrm{~mm}$, a total of 1000 cycles (total sliding distance: $4000 \mathrm{~mm}$ ), at a frequency of $1 \mathrm{~Hz}$. Two surface configurations were tested in lubricated ball-on-disk tests: nanostructures parallel (SS $\|$ ) and perpendicular sliding direction $(\mathrm{SS} \perp)$. In reciprocating pin-on-disc tests both the average value of maximum COF for each cycle and the absolute maximum $\mathrm{COF}$ for each test were measured.

For both configurations, during the tests, friction force was continuously measured by means of a load cell as a function of sliding distance. After the tests, wear scar profiles were determined by stylus profilometry (tip radius: $5 \mu \mathrm{m}$ ). However, detectable wear scar depths were recorded only on the disks in the case of lubricated ball-on-disk tests, as in the dry test the scar shape resulted too shallow and variables along the sliding direction to be accurately measured. Also wear of counterparts was measured by profilometry, but it was non-detectable after all the type of test. The morphology of wear scars on sliders and disks was observed by SEM, in order to identify the dominant wear mechanism.

\section{Results and discussion}

\subsection{Chemical analysis}

The chemical composition of the untreated and NLL-treated stainless steel surfaces was evaluated via XPS analysis. The calculated atomic concentrations of the elements on the untreated and NLL-treated surfaces evaluated via XPS analysis are presented in Table 3. Before the NLL treatment, the detected metals are present on the stainless steel surface both in their metallic and oxidized forms, except $\mathrm{Ni}$, which is present only in the metallic form. After the NLL-treatment the surface was strongly oxidized: the amount of non-oxidized metals was less than $10 \%$. Moreover,
Table 3

XPS chemical analysis (at. \%)of untreated and SS $\|$ NLL-treated surfaces.

\begin{tabular}{|c|c|c|c|c|c|c|c|c|c|}
\hline & $\mathrm{Fe}$ & & $\mathrm{Cr}$ & & $\mathrm{Ni}$ & & Mo & & $\mathrm{O}$ \\
\hline \multirow[t]{3}{*}{ Untreated } & 16.5 & & 5.7 & & 1.3 & & 1.3 & & 75.3 \\
\hline & 13 & 3.5 & 4.7 & 1.0 & $\mathrm{Ni}^{0}$ & & 0.7 & 0.6 & \\
\hline & $\mathrm{Fe}_{2} \mathrm{O}_{3}$ & $\mathrm{Fe}^{0}$ & $\mathrm{Cr}_{2} \mathrm{O}_{3}$ & $\mathrm{Cr}^{0}$ & & & $\mathrm{MoO}_{3}$ & $\mathrm{Mo}^{0}$ & \\
\hline \multirow[t]{3}{*}{ SS $\|$} & 10.0 & & 3.1 & & 2.0 & & 1.6 & & 79.3 \\
\hline & 9.1 & 0.9 & $\mathrm{Cr}_{2} \mathrm{O}_{3}$ & & 1.9 & 0.1 & 1.1 & 0.5 & \\
\hline & $\mathrm{Fe}_{2} \mathrm{O}_{3}$ & $\mathrm{Fe}^{0}$ & & & $\mathrm{NiO}$ & $\mathrm{Ni}^{0}$ & $\mathrm{MoO}_{3}$ & $\mathrm{Mo}^{0}$ & \\
\hline
\end{tabular}

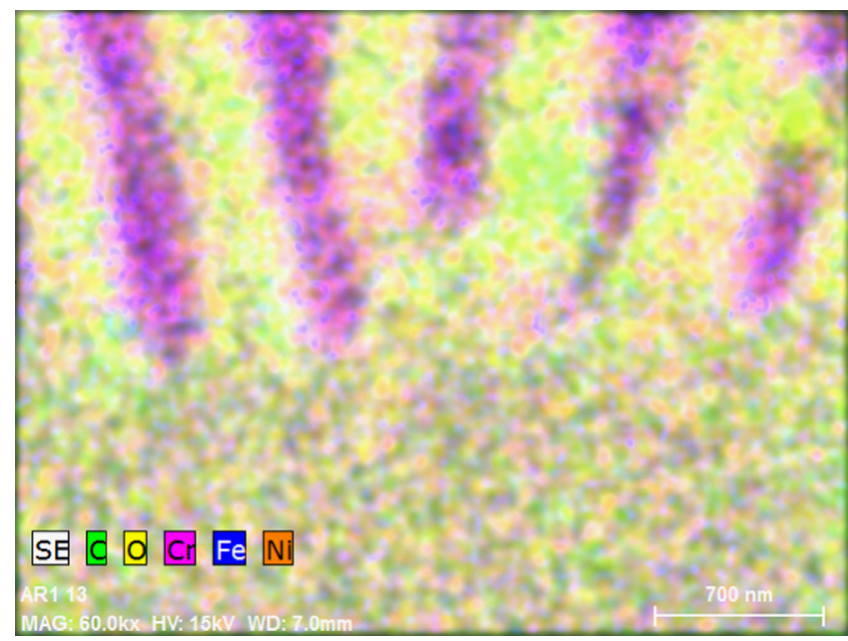

Fig. 3. A representative EDS X-ray map of SS $\|$ NLL-treated surface (stripes produced by the treatment are located in the upper half of the image, whilst the untreated steel is visible in the lower half).

the quantitative ratios of the metals on the surface is changed after NLL-treatment: the Fe:Cr:Ni:Mo ratios are 67:23:5:5 for untreated and 48:34:10:8 for NLL-treated stainless steel surfaces. After the NLL-treatment the surface became less enriched with Fe while other metals migrated to the surface most probably due to the oxidation process. In fact, $\mathrm{Cr}$ and Mo are known to increase the stability of the passive oxide film on stainless steels, while $\mathrm{Ni}$ is effective in promoting repassivation [28]. The analysis of $01 \mathrm{~s}$ spectra demonstrates the increase of oxygen concentration after the NLL-treatment, which correlates with the strong oxidation of the stainless steel surface as a consequence of the NLL-treatment. Fig. 3 shows a representative EDX mapping image of the NLLtreated stainless steel surface, where the bottom part presents a zone which is not treated by the laser. As shown by the EDX map, in the untreated zone the elements are uniformly distributed, 

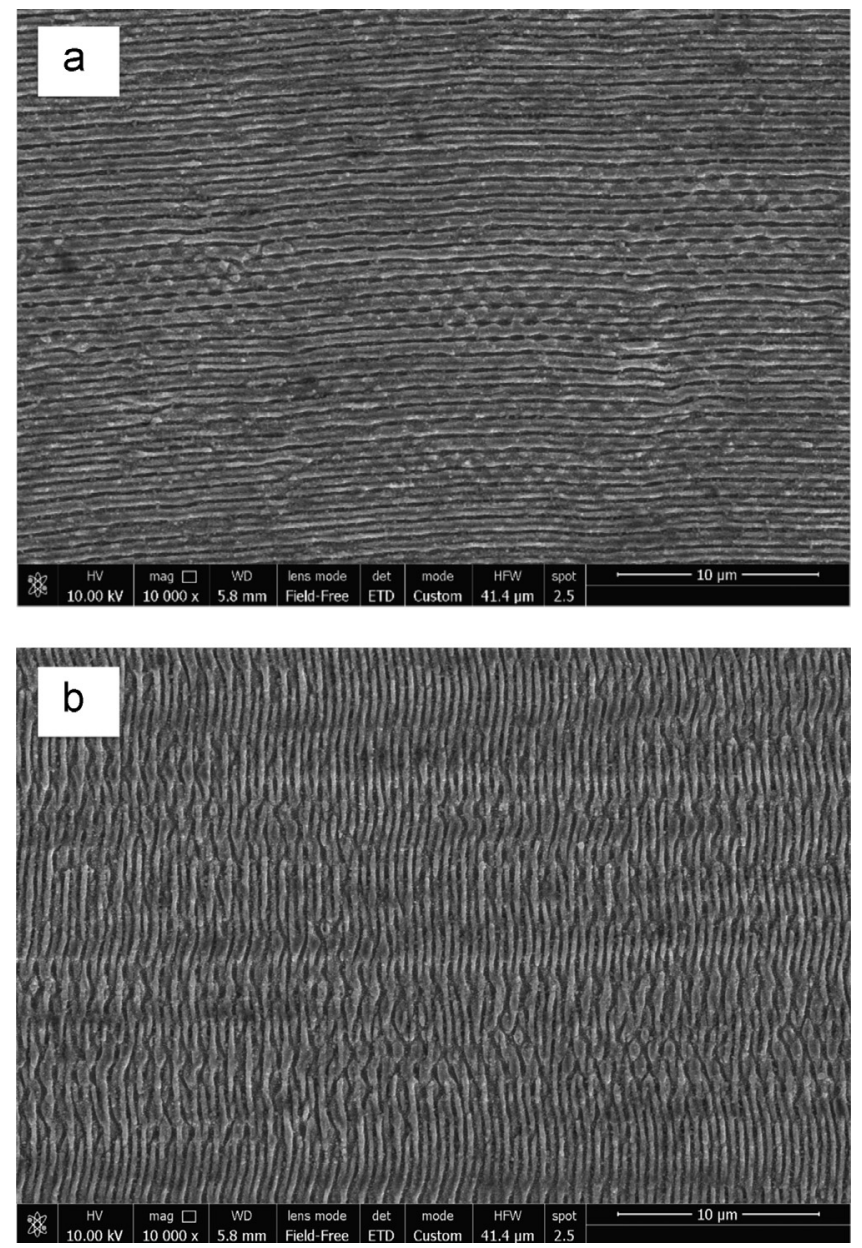

Fig. 4. SEM images of (a) NLL-treated surfaces in $S S \perp$ conditions (perpendicular to the bar length as well as to the sliding direction) and (b) in SS $\|$ conditions (perpendicular to the bar length as well as to the sliding direction).

while in the NLL-treated areas periodic $\mathrm{Fe}-/ \mathrm{Cr}$-enriched stripes and O-enriched stripes are detected. The EDX map clearly shows that $\mathrm{Fe}$ and $\mathrm{Cr}$ are mostly located in the "valleys", whereas oxygen is mostly located on the "peaks" of the nanostructures. The period of the stripes is estimated to be around $800 \mathrm{~nm}$.

\subsection{Morphological analysis}

The morphology of NLL-induced structures was investigated by SEM. Images in Fig. 4 reveal that periodic nanostructures were successfully obtained by irradiation with the linear-polarized femtosecond laser. Images clearly show quite uniform nanostructures that are homogeneously distributed and parallel to each other.

Fig. 4a displays nanostructures obtained in $\mathrm{SS} \perp$ conditions, in which ripples orientation is perpendicular to the sliding direction. The nanostructures homogeneously cover the entire treated zone with an average periodicity of $810 \pm 50 \mathrm{~nm}$.

Fig. 4b shows nanostructures obtained in SS $\|$ conditions: the nanostructures are generated parallel to the longitudinal axis of the steel bar which corresponds to the sliding direction. The average periodicity is comparable to the one observed in $\mathrm{SS} \perp$ conditions, but also double stripes, periodically joining one another with periods $440 \pm 40 \mathrm{~nm}$ were observed.

The direction of the nanoripples is everywhere perpendicular to the laser polarization. The basic mechanism of created LIPSS is

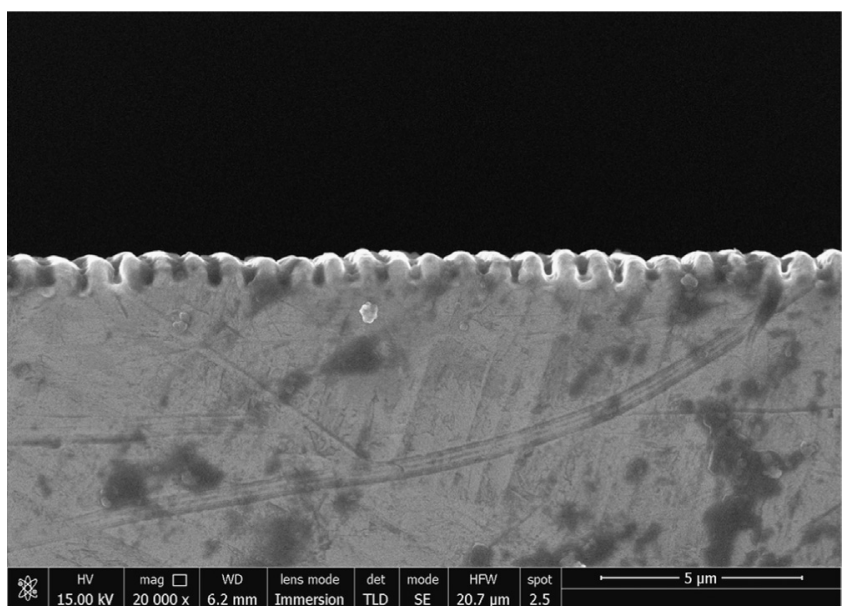

Fig. 5. SEM image (cross section) of the NLL-treated surfaces in SS $\|$ conditions, displaying the high height/width aspect ratio of the nanostructures.

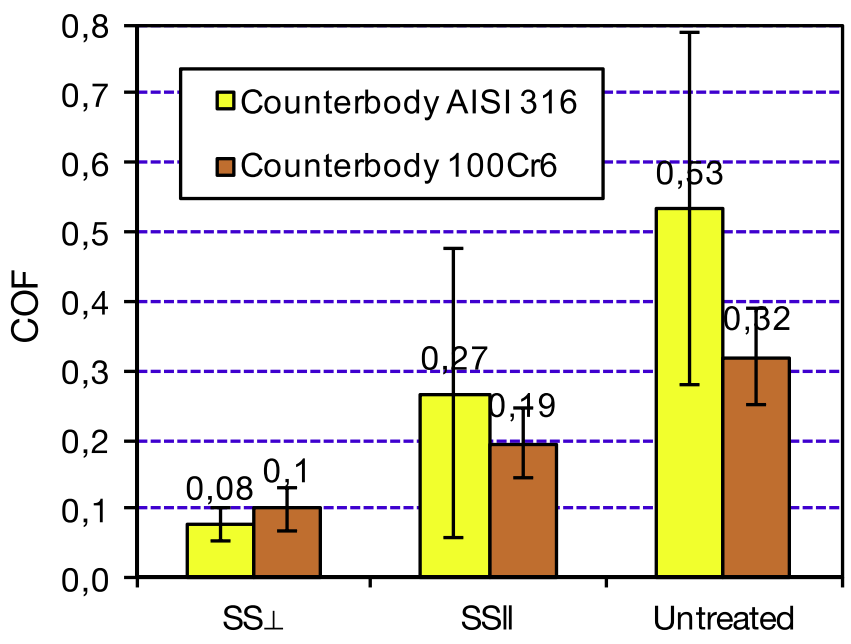

Fig. 6. Dry sliding tests: Coefficient of friction (COF, averaged over the first $10 \mathrm{~m}$ of sliding) of AISI 316L, untreated or treated with different orientations of the NLLtreated surfaces (SS $\perp$ : perpendicular; SS $\|$ : parallel) vs. different countermaterials: (a) AISI 316L and (b) EN 100Cr6.

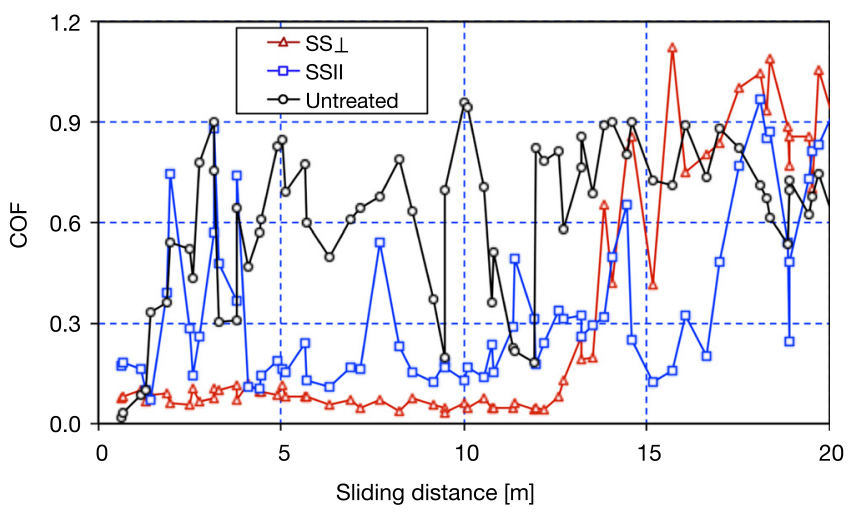

Fig. 7. Dry sliding tests: coefficient of friction as a function of sliding distance for untreated or LIPSS-textured AISI 316L steel, sliding against AISI 316L. Two different orientations of the textured surface ( $\mathrm{SS} \perp$ : perpendicular; $\mathrm{SS} \|$ : parallel to the sliding direction) are compared.

interaction of the incident laser beam with a surface plasmon polaritons (SPPs) [29]. However, NLL principles, such as positive and negative feedbacks and the coherent propagation of the nanostructures along the surface are preserved [22].

Cross-sectional SEM image in Fig. 5 shows the profile of the obtained nanostructures. The height to width aspect ratio of the 
ripples is not lower than 1 . This suggests that significant effects in changing wettability/tribological properties of the NLL-treated surface might be expected.

We should note that proposal technique has clear advantage in term of productivity. Currently it is $60 \mathrm{~mm}^{2} \mathrm{~min}^{-1}$ and potentially can be even higher. At least this in two times more respect to those reported by [19].

\subsection{Tribological tests}

\subsubsection{Dry sliding}

The histograms in Fig. 6 show the average COF values, evaluated in the steady-state portion of the friction vs. distance plots (such as those in Fig. 7). The results in Fig. 6 indicate that the average COF of NLL-treated surfaces is smaller than that of
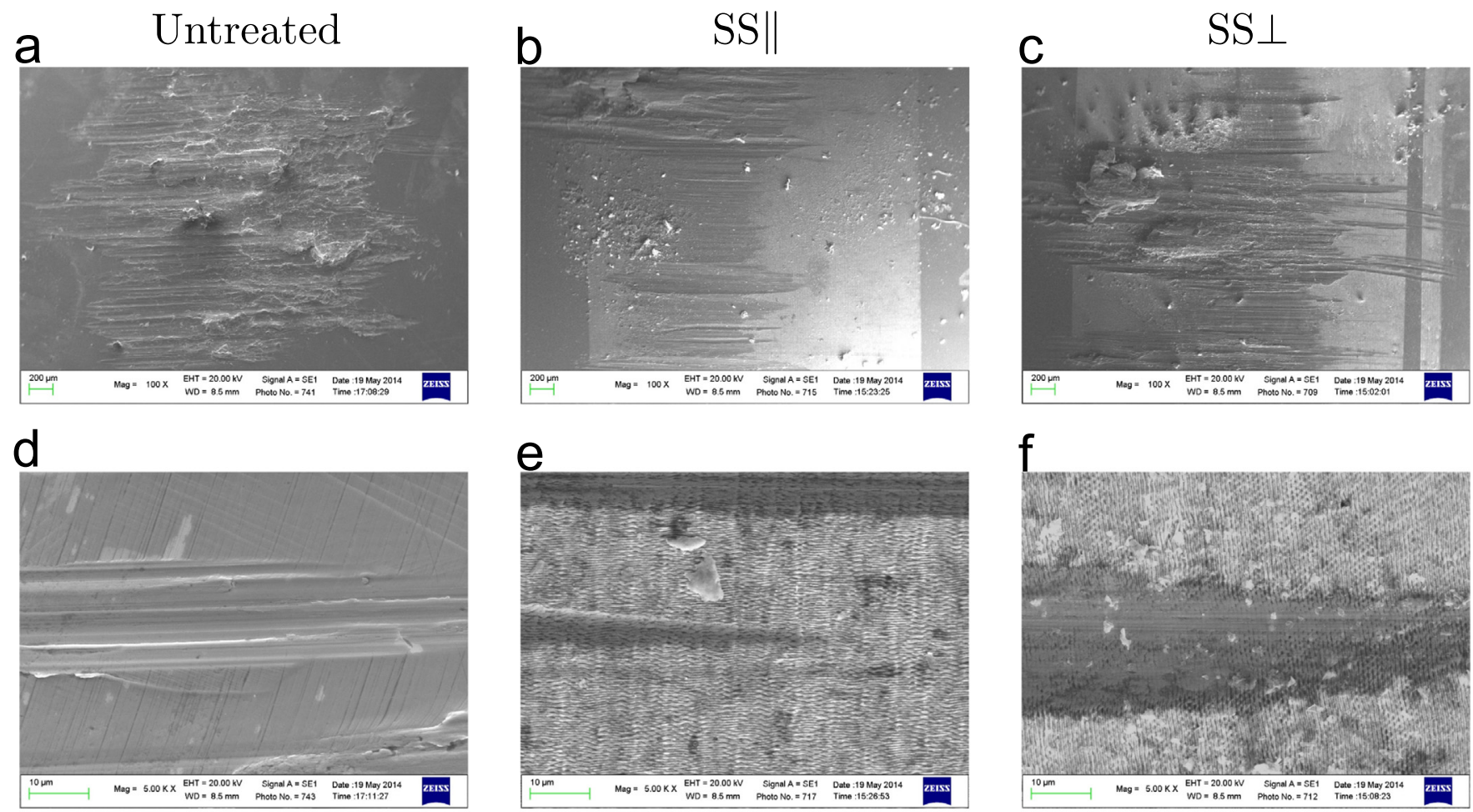

9
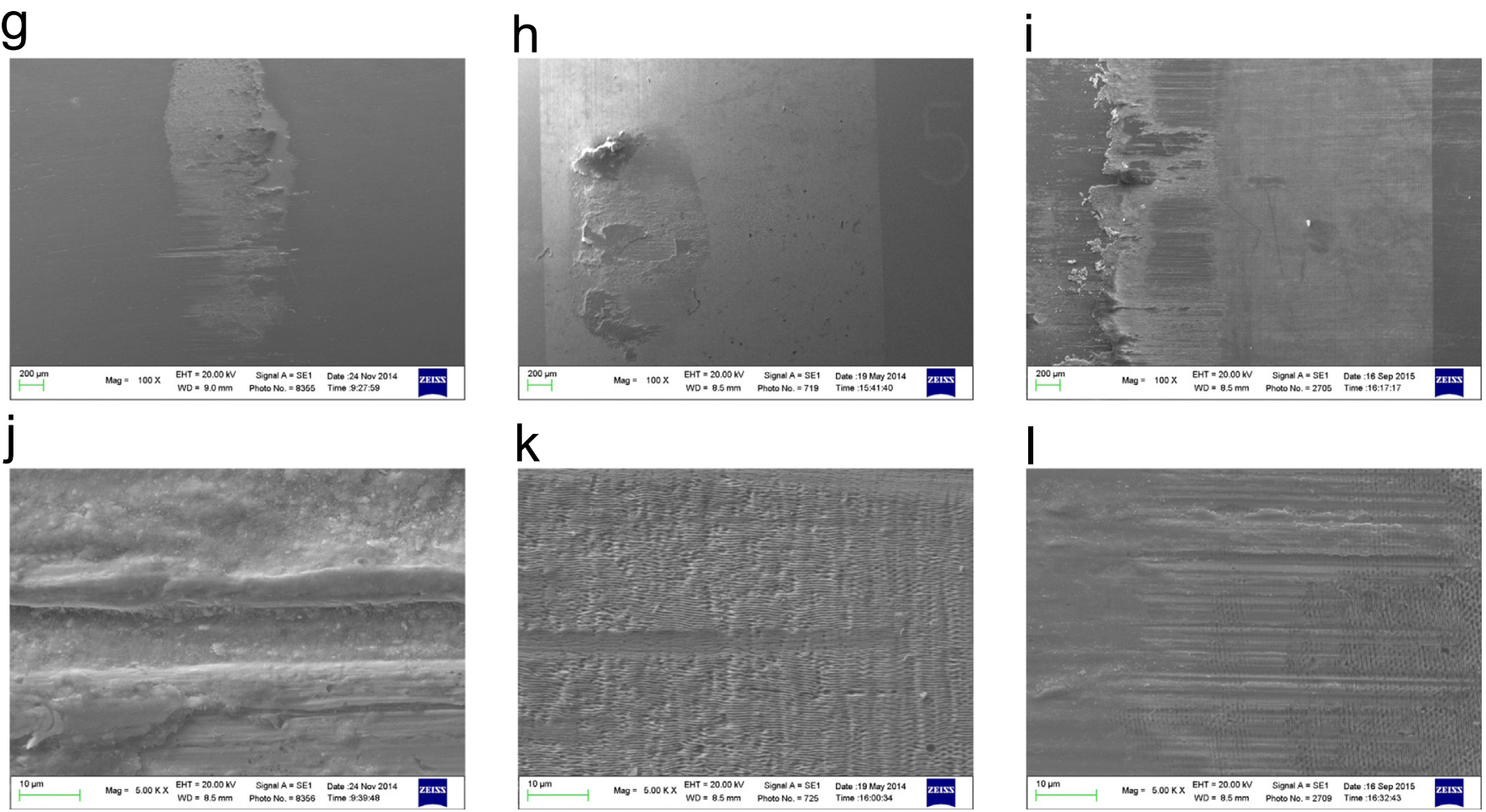

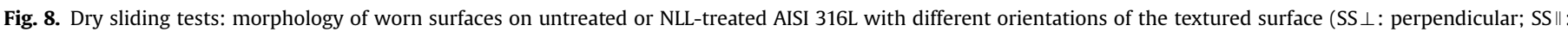

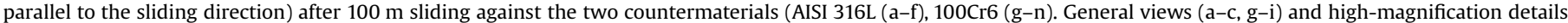
(d-f, l-n). 
Table 4

Comparison between the composition of unworn surfaces and of wear scars, EDS data (wt.\%). The measurements were recorded in images shown in. Fig. 8.

\begin{tabular}{|c|c|c|c|c|c|c|c|c|c|c|c|}
\hline Sample & Counter material & Image & Spectrum & C & $\mathbf{0}$ & Si & $\mathrm{Cr}$ & Mn & $\mathbf{F e}$ & $\mathbf{N i}$ & Mo \\
\hline Untreated & AISI316L & $8 a$ & Wear scar & 2.48 & 1.66 & 0.47 & 17.05 & 1.72 & 65.29 & 9.21 & 2.12 \\
\hline Untreated & AISI316L & $8 a$ & Unworn & 2.06 & 0.90 & 0.47 & 17.50 & 1.64 & 65.66 & 9.39 & 2.38 \\
\hline $\mathrm{SS} \perp$ & AISI316L & $8 c$ & Wear scar & 2.93 & 3.76 & 0.47 & 17.05 & 1.72 & 65.29 & 9.21 & 2.12 \\
\hline $\mathrm{SS} \perp$ & AISI316L & $8 c$ & Unworn & 2.11 & 0.98 & 0.46 & 17.88 & 1.64 & 65.23 & 9.44 & 2.26 \\
\hline Untreated & $100 \mathrm{Cr} 6$ & $8 g$ & Wear scar & 3.79 & 30.30 & 0.35 & 6.95 & 0.86 & 54.41 & 2.63 & 0.71 \\
\hline Untreated & $100 \mathrm{Cr} 6$ & $8 \mathrm{~g}$ & Unworn & 11.08 & 1.59 & 1.07 & 13.64 & 1.43 & 59.70 & 9.68 & 1.81 \\
\hline $\mathrm{SS} \perp$ & $100 \mathrm{Cr} 6$ & $8 \mathrm{i}$ & Wear scar & 4.25 & 32.09 & 0.33 & 5.77 & 0.62 & 54.21 & 2.10 & 0.63 \\
\hline $\mathrm{SS} \perp$ & $100 \mathrm{Cr} 6$ & $8 \mathrm{i}$ & Unworn & 12.42 & 2.33 & 1.26 & 12.75 & 1.29 & 59.07 & 9.21 & 1.67 \\
\hline
\end{tabular}

untreated surfaces, regardless the countermaterial. Regarding the influence of the countermaterial, in the self-mating AISI 316L vs. AISI 316L contact, the COFs are generally higher (for both untreated and NLL-treated steel) than against EN100Cr6 (Fig. 6), due to the higher adhesive contribution to friction [30]. Concerning the influence of the NLL treatment orientation, against both countermaterials the NLL-treated steels with perpendicular orientation display the lowest COF values, as observed also by other authors [31]. The perpendicular alignment probably generates a lower contact area between the asperities of the mating surfaces, which in turn induces a lower adhesive component of friction. This hypothesis is also presented in [32], when discussing the influence of micro/nanogrooved surfaces on friction. A shorter stiction length contributes to decrease the friction coefficient, measured in the perpendicular orientation on samples with narrow grooves, if the ratio between the width of the grooves (b) and the radius of counterbody ( $R$ ) is less than $10^{-3}$, as in the case of the present work where $b / R$ is about $2.5 \cdot 10^{-5}$.

A more detailed analysis of the evolution of friction as a function of sliding distance in the self-mating configuration (AISI 316L vs. AISI 316L) is shown in Fig. 7. The comparison of dynamic friction curves shows that, while the untreated steel displays high COF and undergoes wide oscillations (typical of stick-slip motion in sliding systems at low speed and high adhesion [33]), the NLLtreated steel displays low COF, especially when the orientation of the texture is perpendicular to the sliding direction. Specifically, the perpendicular orientation generates the lowest values of dynamic friction in Fig. 7, with negligible oscillations during sliding, up to a distance of $12 \mathrm{~m}$. Then, the COF increases with increasing sliding distance and starts to display remarkable oscillations, similar to those showed by the untreated steel as well as by the treated steel with parallel orientation (even though to a lower extent). This transition to high friction is due to the onset of wear damage of the NLL-treated surface, as demonstrated by morphological observation of the worn surfaces.

The morphology of wear scars observed by SEM at the end of dry sliding tests is shown in Fig. 8. When sliding in the self-mating configuration (AISI 316L vs. AISI 316L), the untreated steel surface (Fig. 8a and d) clearly undergoes heavy plastic deformation and shows no evidence of the typical protective oxide layer, which usually forms under low loads such as $5 \mathrm{~N}$, but with higher sliding distances than those used in the present study [34]. On the contrary, the NLL-treated surfaces are, already after these short tests, partly covered with fine oxidized wear debris (powdery material is visible at low magnification in Fig. 8b and c and dark grey oxidized areas are visible in high-magnification images of Fig. 8e and f).

Table 4 reports EDS data showing higher concentrations of $\mathrm{O}$ in the worn surfaces of NLL-treated steel with perpendicular orientation than in the untreated steel. So, even though the oxide debris coverage is never continuous, oxides were observed to a higher extent on the surface with perpendicular orientation (Fig. 8c and f), where the entrapment of debris, "wave after wave" along the sliding direction, might be favoured. With a parallel orientation,
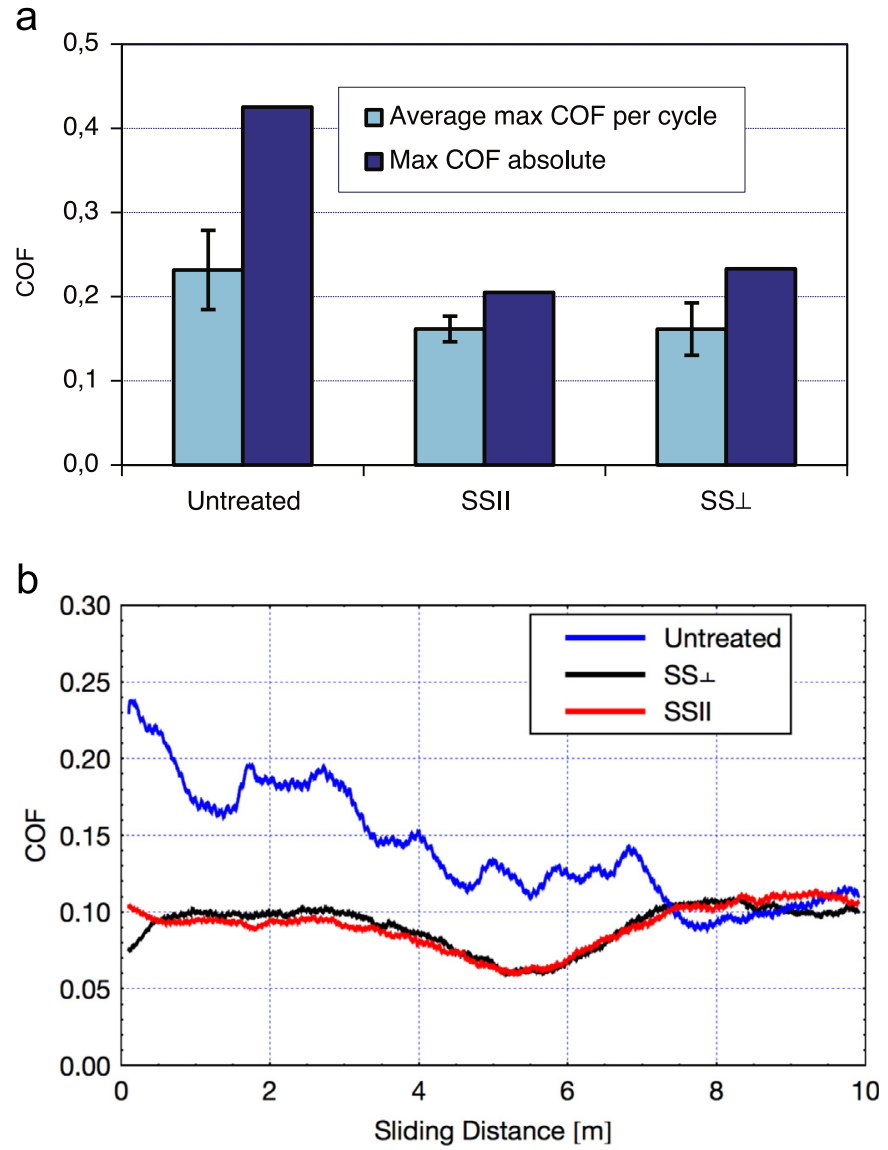

Fig. 9. Lubricated sliding tests: (a) COF maximum values and average of the maximum COF for each cycle of AISI 316L, untreated or treated with different orientations (SS $\perp$ : perpendicular; $S S \|$ : parallel); (b) dynamic COF values as a function of sliding distance for untreated and $\mathrm{SS} \perp$ textured steel.

instead, oxides may be more easily removed from the bottom of the grooves aligned with the sliding direction.

When sliding against $100 \mathrm{Cr} 6$, the untreated steel surface (Fig. 8g and l) underwent plastic deformation, even though to a lesser extent than in the self-mating configuration. This is due to a lower incidence of adhesion phenomena (as shown by the comparison of Fig. 8a and g). Moreover, the worn surfaces are covered with a protective iron-oxide transfer layer, which was thicker and more continuous than when sliding against AISI 316L. Correspondingly, higher $\mathrm{O}$ concentrations were measured on the wear scars (Table 4).

As already observed for the previous tribological coupling, the surface of the NLL-treated steel (Fig. $8 \mathrm{~m}$ and $\mathrm{n}$ ) is less damaged than untreated steel (Fig. 81). The nanotextured surface with perpendicular orientation (Fig. $8 \mathrm{i}$ and $\mathrm{n}$ ) seems to be able to stabilize a 
more continuous iron oxide layer than the parallel one (Fig. $8 \mathrm{~h}$ and $\mathrm{m}$ ).

In general, the presence of iron oxides on the worn surface, which is typical of dry sliding contacts involving AISI 316L stainless steel under low loads and speeds [35-37] and [38,39], can play a significant role in decreasing friction. The ability of lasertextured surfaces to trap wear debris, which is the main mechanism for the improvement of tribological behaviour in dry conditions [40], may further enhance the beneficial role of iron oxides in decreasing friction.

The wear debris are more efficiently retained on the textured surface with perpendicular orientation due to geometrical factors, thus producing the lowest COF values when dry sliding against both countermaterials.

\subsubsection{Lubricated sliding tests}

As already observed in dry sliding tests, the average COF values measured in lubricated conditions Fig. 9a indicate that NLLtreatment is able to decrease the COF of the AISI 316L austenitic stainless steel. Fig. 9b shows an example of the dynamic evolution of $\mathrm{COF}$ as a function of sliding distance during lubricated sliding tests for the untreated steel and for the $\mathrm{SS} \perp$ configuration. As already observed in dry sliding conditions, for the untreated steel the average values of COF are higher, the oscillations are wider and the general trend is less homogeneous than in the case of the NLLtreated steel.

In lubricated conditions, however, the effect of the nanostructure orientation (perpendicular or parallel to the sliding direction) seems to be less prominent than in dry sliding

\section{Untreated}

\section{a}

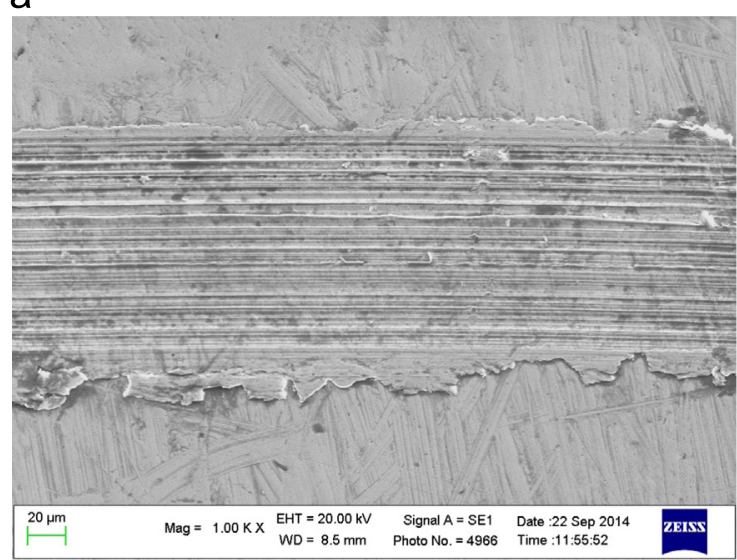

C

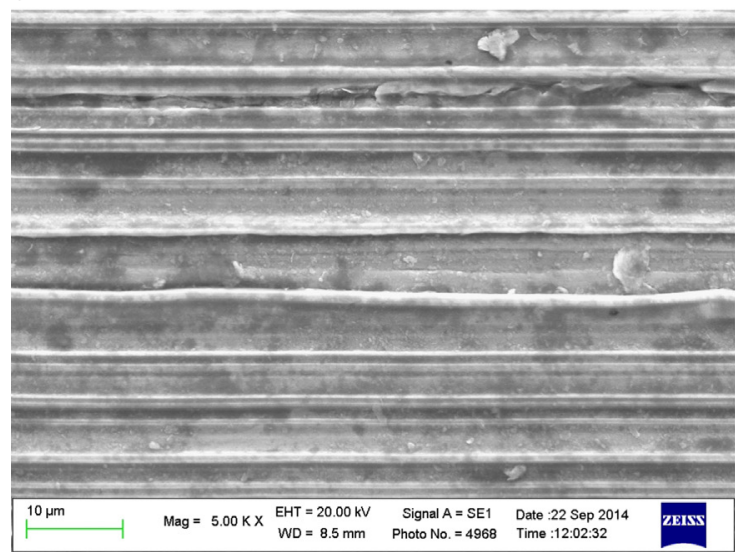

conditions: both the parallel and the perpendicular orientation is effective in decreasing COF, with no remarkable difference between the two.

This is probably due to the ability of both the orientations to increase lubricant retention on the steel surface, thus limiting the two main components of friction: (i) adhesion due to steel-to-steel contact and (ii) abrasion of the soft AISI 316L surface by the hard $100 \mathrm{Cr} 6$ sphere. In addition to an increased lubricant retention effect, which is listed among the main mechanisms for the beneficial influence of laser texturing in lubricated sliding [40], also other non-directional effects might have a beneficial influence on friction. In particular, in lubricated sliding, also other authors [41] observed that the textured surfaces (regardless the shape and orientation of texture) proved to be beneficial and showed rather similar friction behaviours. They attributed the generalized beneficial role of texture to the ability of grooves and depressions of (i) getting the interface rid of loose abrasive particles and (ii) acting as "interruptions" of surface deformation, thus generally limiting possibilities for local contact area growth.

In the case of lubricated reciprocating sliding, the wear scars (Fig. 10) were much more homogeneous than in the case of dry sliding (as demonstrated by the comparison between Figs. 8 and 10). Also, the iron oxide transfer layers which were discussed previously for dry sliding tests (Section 3.3.1) and which stabilize on the NLL-treated surface to an extent depending on the orientation, were not observed. In lubricated sliding, the lubricant is likely to maintain a lower contact temperature than in dry sliding, thereby limiting oxidation phenomena [42].

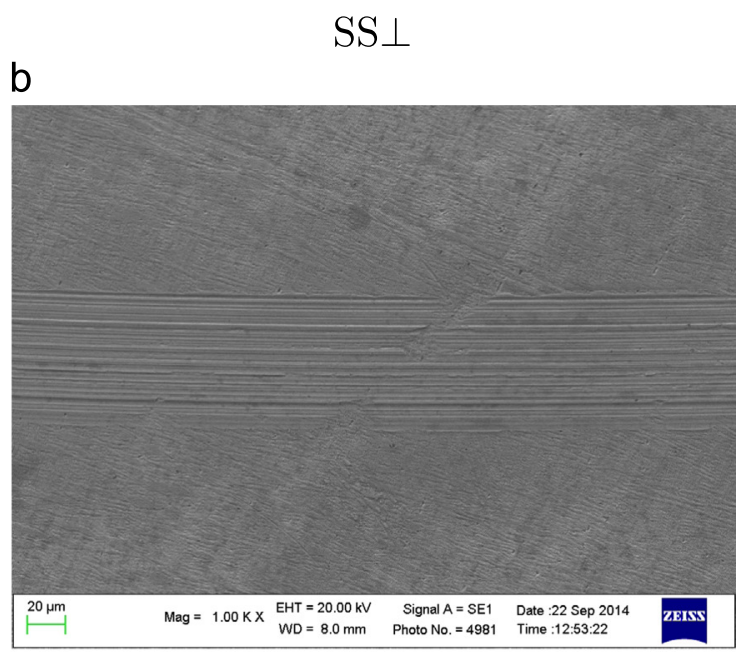

d

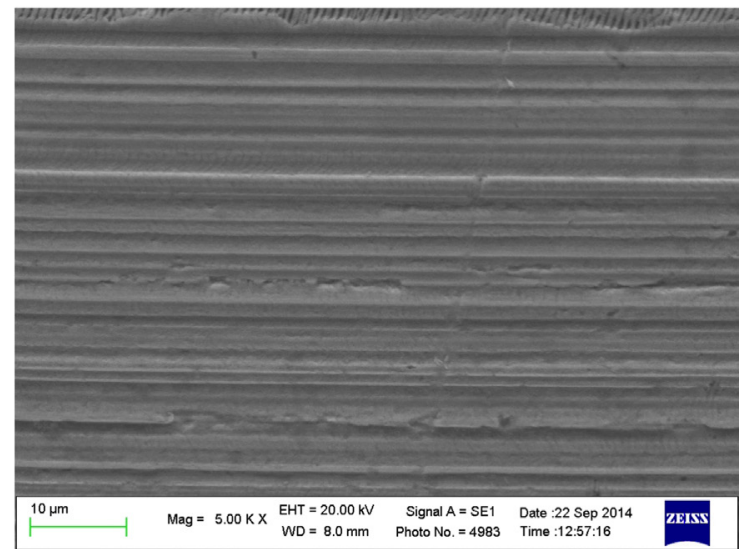

Fig. 10. Lubricated sliding tests: SEM images of the worn surfaces on untreated (a and c) or NLL-treated AISI 316L with perpendicular orientation (SS $\perp$, b and d). 


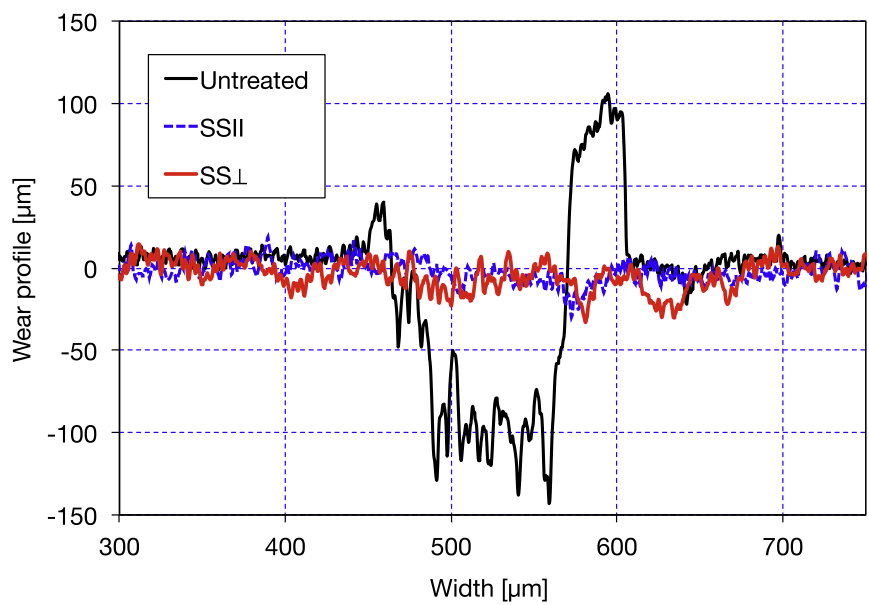

Fig. 11. Lubricated sliding tests: comparison of surface profiles measured across the wear scars by stylus profilometry on NLL-treated and untreated steel surfaces.

Due to the homogeneity of wear scars obtained in lubricated conditions, it was possible to measure representative depth profiles, as those compared in Fig. 11, which shows that detectable values of wear depth were obtained only in the case of untreated steel (depth $\approx 100 \mu \mathrm{m}$ ). The NLL-treated steel surfaces only show a few, shallow grooves and scratches (as shown also by the SEM images in Fig. 10b and d). The untreated steel also shows the typical plastic deformation at the side of the wear scar (due to ploughing), which is absent from the NLL-treated surfaces. Therefore, also in this case, the improved friction and wear behaviour of NLL-treated surfaces might be attributed to restricted possibilities for plastic deformation and hence for local contact area growth.

\section{Conclusions}

The sliding behaviour of AISI 316L austenitic stainless steel was investigated before and after surface nanopatterning by Nonlinear Laser Lithography (NLL). Sub-wavelength nano-ripples with a good uniformity and on large areas were generated with different orientations to the sliding direction (perpendicular or parallel) and their influence on the tribological properties was investigated. Both dry (block-on-ring) and lubricated (ball-on-disk contact geometry) sliding tests were carried out, using different counterbody materials. The following conclusions can be drawn from this work:

- The NLL treatment produces a significant reduction of the coefficient of friction both in dry and lubricated conditions.

- In dry sliding conditions, the friction reduction depends on the orientation of the nanogrooves with respect to the sliding direction: the best results were obtained by the perpendicular orientation.

- In dry conditions, the beneficial influence of NLL on friction was attributed to the ability of the nanogrooves (i) to lower the contact area between the asperities of the mating surfaces, hence to reduce adhesion and (ii) to entrap the iron oxide wear debris. The first effect dominates in the AISI 316L-AISI 316L selfmating contact, whereas the second one is the main effect in the case of sliding against $100 \mathrm{Cr} 6$.

- In lubricated conditions, the decrease of friction induced by NLL is not significantly affected by the relative orientation between nanotextures and sliding. The beneficial influence of NLL on friction was attributed to the increased lubricant retention as well as to ability of the nanogrooves to limit plastic deformation and hence local contact area growth.

\section{Acknowledgements}

We acknowledge funding from ERC Grant ERC-617521 NLL. We would like moreover to thank Massimo Tonelli and Mauro Zaparolli (CIGS-University of Modena and Reggio Emilia) for the SEM characterizations.

\section{References}

[1] Peckner D, Bernstein IM. Handbook of stainless steels, vol. 27. New York: Mc Graw-Hill, 2007.

[2] Magee JH. Wear of stainless steels, ASM handbook online, friction, lubrication, and wear technology, vol. 18. ASM International, Materials Park, $\mathrm{OH}$.

[3] Hsu KL, Ahn TM, Rigney DA. Wear of stainless steels, friction, wear and microstructure of unlubricated austenitic stainless steels. ASM Int 1980;60:13-37.

[4] Holmberg K, Matthews A. Coatings tribology: properties, mechanisms, techniques and applications in surface engineering, second ed. Elsevier: Amsterdam.

[5] Andersson P, Koskinen J, Varjus S, Gerbig Y, Haefke H, Georgiou S, et al. Microlubrication effect by laser-textured steel surfaces. Wear 2007;262(34):369-79.

[6] Qiu Y, Khonsari MM. Experimental investigation of tribological performance of laser textured stainless steel rings. Tribol Int 2011;44(5):635-44.

[7] Ramesh A, Akram W, Mishra SP, Cannon AH, Polycarpou AA, King WP. Friction characteristics of microtextured surfaces under mixed and hydrodynamic lubrication. Tribol Int 2013;57:170-6.

[8] Braun D, Greiner C, Schneider J, Gumbsch P. Efficiency of laser surface texturing in the reduction of friction under mixed lubrication. Tribol Int 2014;77:142-7.

[9] Scaraggi M, Mezzapesa FP, Carbone G, Ancona A, Sorgente D, Lugará PM. Minimize friction of lubricated laser-microtextured-surfaces by tuning microholes depth. Tribol Int 2014;75:123-7.

[10] Daschiel G, Perić M, Jovanović J, Delgado A. The holy grail of microfluidics: sub-laminar drag by layout of periodically embedded microgrooves. Microfluid Nanofluidics 2013;15(5):675-87.

[11] Bonse J, Krüger J, Höhm S, Rosenfeld A. Femtosecond laser-induced periodic surface structures. J Laser Appl 2012;24(4):042006.

[12] Vorobyev AY, Guo C. Femtosecond laser nanostructuring of metals. Opt Express 2006;14(6):2164-9.

[13] Yasumaru N, Sentoku E, Miyazaki K, Kiuchi J. Femtosecond-laser-induced nanostructure formed on nitrided stainless steel. Appl Surf Sci 2013;264:611-5.

[14] Le Harzic R, Dörr D, Sauer D, Neumeier M, Epple M, Zimmermann H, et al. Large-area, uniform, high-spatial-frequency ripples generated on silicon using a nanojoule-femtosecond laser at high repetition rate. Opt Lett 2011;36 (2):229-31.

[15] Hong L, Rusli, Wang XC, Zheng HY, Wang H, Yu HY. Femtosecond laser fabrication of large-area periodic surface ripple structure on Si substrate. Appl Surf Sci 2014;297:134-8.

[16] Birnbaum M. Semiconductor surface damage produced by ruby lasers. J Appl Phys 1965;36(11):3688-9.

[17] Vorobyev AY, Guo C. Femtosecond laser structuring of titanium implants. Appl Surf Sci 2007:253(17):7272-80.

[18] Bonse RKJ. Femtosecond laser-induced periodic surface structures on steel and titanium alloy for tribological applications. Appl Phys A 2014;117(1):103-10.

[19] Bonse J, Koter R, Hartelt M, Spaltmann D, Pentzien S, Höhm S, et al. Tribological performance of femtosecond laser-induced periodic surface structures on titanium and a high toughness bearing steel. Appl Surf Sci 2015;336:21-7.

[20] Ruiz De La Cruz A, Lahoz R, Siegel J, De La Fuente GF, Solis J. High speed inscription of uniform, large-area laser-induced periodic surface structures in Cr films using a high repetition rate fs laser. Opt Lett 2014;39(8):2491-4.

[21] Huang M, Zhao F, Cheng Y, Xu N, Xu Z. Large area uniform nanostructures fabricated by direct femtosecond laser ablation. Opt Express 2008;16 (23):19354-65.

[22] Öktem B, Pavlov I, Ilday S, Kalaycıoğlu H, Rybak A, Yavaş S, et al. Nonlinear laser lithography for indefinitely large-area nanostructuring with femtosecond pulses. Nat Photonics 2013;7(11):897-901.

[23] Moulder J, Stickle W, Sobol P, Bomben J, KD. In: Chastain, editor. Handbook of X-Ray Photoelectron Spectroscopy, Perkin-Elmer, Eden Prairie, Minnesota; 1992.

[24] ASTM G77-05(2010), Standard test method for ranking resistance of materials to sliding wear using block-on-ring wear test; 2010.

[25] Ceschini L, Martini C, Rotundo F. Sliding contacts for the pharmaceutical industry: failure analysis and dry sliding tests for the replacement of hard $\mathrm{Cr}$ on AISI 316L steel. Tribol Int 2015;81:248-57. 
[26] Bhushan B. Modern tribology handbook, two volume set. CRC Press; Boca Raton, FL: 2000.

[27] ASTM G99-05(2010), Standard test method for wear testing with a pin-ondisk apparatus; 2010.

[28] Washko SD, Aggen G. Properties and selection: irons, steels, and highperformance alloys, wrought stainless steels, ASM Handbook. ASM International; Materials Park, OH: 1990.

[29] Sipe JE, Young JF, Preston JS, Van Driel HM. Laser-induced periodic surface structure i. theory. Phys Rev B 1983;27(2):1141-54.

[30] Hutchings IM. Tribology: friction and wear of engineering materials. Elsevier Limited; Amsterdam, NL.

[31] Rosenkranz A, Reinert L, Gachot C, Mücklich F. Alignment and wear debris effects between laser-patterned steel surfaces under dry sliding conditions. Wear 2014;318(1-2):49-61.

[32] Yu C, Yu H, Liu G, Chen W, He B, Wang QJ. Understanding topographic dependence of friction with micro- and nano-grooved surfaces. Tribol Lett 2014;53(1):145-56.

[33] Stachowiak GW, Batchelor AW. 10 fundamentals of contact between solids. In: Batchelor GWSW, editor. Engineering tribology, third ed. Burlington: Butterworth-Heinemann; 2006. p. 461-99.

[34] Ceschini L, Chiavari C, Marconi A, Martini C. Influence of the countermaterial on the dry sliding friction and wear behaviour of low temperature carburized AISI316l steel. Tribol Int 2013;67:36-43.
[35] Smith AF. The friction and sliding wear of unlubricated 316 stainless steel at room temperature in air. Wear 1984;96(3):301-18.

[36] Smith AF. The influence of surface oxidation and sliding speed on the unlubricated wear of 316 stainless steel at low load. Wear 1985;105(2):91-107.

[37] Smith AF. The friction and sliding wear of unlubricated 316 stainless steel in air at room temperature in the load range 0.5-90 n. Wear 1986;110(2):151-68.

[38] O'Donnell LJ, Michal GM, Ernst F, Kahn H, Heuer AH. Wear maps for low temperature carburised 3161 austenitic stainless steel sliding against alumina. Surf Eng 2010;26(4):284-92.

[39] Rotundo F, Ceschini L, Martini C, Montanari R, Varone A. High temperature tribological behavior and microstructural modifications of the lowtemperature carburized AISI 3161 austenitic stainless steel. Surf Coat Technol 2014;258:772-81.

[40] Etsion I. State of the art in laser surface texturing. ASME J Tribol 2005; 127:248-53.

[41] Pettersson U, Jacobson S. Textured surfaces for improved lubrication at high pressure and low sliding speed of roller/piston in hydraulic motors. Tribol Int 2007;40(2):355-9.

[42] Hong H-S. The role of atmospheres and lubricants in the oxidational wear of metals. Tribol Int 2002;35(11):725-9. 